SILVA, V.F.; BEZERRA NETO, F.; NEGREIROS, M.Z.; PEDROSA, J.F. Comportamento de cultivares de alface em diferentes espaçamentos sob temperatura e luminosidade elevadas. Horticultura Brasileira, Brasília, v. 18 n. 3, p. 183-187, novembro 2.000 .

\title{
Comportamento de cultivares de alface em diferentes espaçamentos sob temperatura e luminosidade elevadas.
}

\author{
Villegaignon Ferreira da Silva; Francisco Bezerra Neto; Maria Zuleide de Negreiros; Josué Fernandes \\ Pedrosa \\ ESAM - Departamento de Fitotecnia, Km 47 BR 110, C. Postal 137, 59.625-900, Mossoró-RN. e.mail: bezerra@esam.br
}

\begin{abstract}
RESUMO
O comportamento de três cultivares de alface em seis diferentes espaçamentos de plantio sob temperatura e luminosidade elevadas foi avaliado no período de 8 de junho a 24 de julho de 1998, na Horta do Departamento de Fitotecnia da ESAM em Mossoró (RN). O delineamento experimental usado foi blocos casualizados completos com quatro repetições em um esquema fatorial $3 \times 6+1$ (tratamento adicional). Os tratamentos consistiram da combinação de três cultivares de alface (Great Lakes, Elisa e Babá de Verão) com seis espaçamentos de plantio $(20 \times 20 \mathrm{~cm}, 20 \times 25 \mathrm{~cm}, 20 \times 30 \mathrm{~cm}$, $25 \times 25 \mathrm{~cm}, 25 \times 30 \mathrm{~cm}$ e $30 \times 30 \mathrm{~cm}$ ) mais um tratamento adicional que foi a cultivar Great Lakes, no espaçamento $20 \times 20 \mathrm{~cm}$, sombreada durante todo o ciclo cultural. As características avaliadas foram altura e diâmetro de plantas, número de folhas por planta, massa seca da parte aérea, produtividade, renda bruta, renda líquida e taxa de retorno. A cultivar Great Lakes foi a que apresentou melhor produtividade e melhores indicadores econômicos. $\mathrm{O}$ espaçamento que apresentou maior produção de massa seca da parte aérea, produtividade e os maiores indicadores econômicos foi 20 x $20 \mathrm{~cm}$. O número de folhas por planta foi superior para a cultivar Elisa, mas não foi afetado pelos espaçamentos.
\end{abstract}

Palavras-chave: Lactuca sativa L., sombreamento, produtividade.

\begin{abstract}
Effects of lettuce cultivars and spacings on lettuce leaf yield under high temperature and sunlight.

An experiment was carried out from June 8th to July 24th, 1998, in the Departamento de Fitotecnia, ESAM, Brazil, to evaluate the performance of three lettuce cultivars in six different planting spacings on lettuce leaf yield under high temperature and ample sunlight. The experimental design was a randomized complete block in a $3 \times 6+$ 1(additional treatment) factorial scheme, with four replications. The treatments were the combination of three lettuce cultivars (Great Lakes, Elisa and Babá de Verão) and six planting spacings $(20 \times 20 \mathrm{~cm}, 20 \mathrm{x}$ $25 \mathrm{~cm}, 20 \times 30 \mathrm{~cm}, 25 \times 25 \mathrm{~cm}, 25 \times 30 \mathrm{~cm}$ and $30 \times 30 \mathrm{~cm}$ ) plus one additional treatment (Great Lakes in the $20 \times 20 \mathrm{~cm}$ spacing under shading throughout the crop cycle). Evaluations were performed for plant height and diameter, leaf number per plant, shoot dry matter content, leaf yield, gross and net incomes, and rate of return. The cultivar Great Lakes had the greatest leaf yield and economic indices. The best spacing regarding leaf yield, shoot dry matter content, and economic indices was $20 \times 20 \mathrm{~cm}$. Leaf number per plant was higher in the cultivar Elisa but was not affected by spacings.
\end{abstract}

Keywords: Lactuca sativa L., shading, leaf yield.

\section{(Aceito para publicação em 13 de setembro de 2.000)}

A alface é uma das hortaliças folhosas mais consumidas no Brasil. Em virtude de sua alta perecibilidade e baixa resistência ao transporte, é cultivada próxima aos grandes centros consumidores, nos chamados "cinturões verdes". No Rio Grande do Norte, os plantios comerciais desta hortaliça estão localizados na área metropolitana da capital, com uso de tecnologias modernas de cultivo e mão-de-obra especializada. No interior do Estado, os plantios são efetuados nas denominadas "hortas de fundo de quintal", por pequenos produtores, utilizando mão-de-obra familiar, de forma empírica e com tecnologia rudimentar, o que tem contribuído para uma produção insuficiente para atender a demanda, necessitando de importação de outros estados.

A adaptação da alface a temperatura e luminosidade elevadas tem impe- dido que a cultura expresse todo o seu potencial genético, afetando o desenvolvimento das folhas, tornando-as fibrosas, reduzindo o seu ciclo cultural, permitindo a não formação de cabeças e comprometendo a sua produção, devido à antecipação da fase reprodutiva (Makishima, 1992; Setúbal \& Silva,1992). O uso de cultivares adaptadas a essas condições ambientais, como também o emprego de práticas que visem à diminuição dos efeitos da luminosidade e da temperatura, podem contribuir para o aumento de sua produtividade. Um dos grandes desafios aos pesquisadores da Região Semi-árida Nordestina tem sido obter cultivares de alface que se adaptem às condições de temperatura e luminosidade elevadas.

Leal \& Souza (1991), estudando o comportamento de sete cultivares de alface em Teresina pelo sistema tradicio- nal de plantio, verificaram que as cultivares que destacaram-se como superiores foram Gorga, Boston Branca, Maravilha de Verão e Babá de Verão. Lyra Filho et al. (1994), avaliaram o comportamento de cultivares de alface do grupo de folhas lisas nas condições da Zona da Mata de Pernambuco, no período de julho a setembro de 1993, verificando que de onze cultivares estudadas, utilizando o espaçamento de $25 \times 25 \mathrm{~cm}$, as cultivares Elisa e Maravilha de Inverno foram as que melhor se comportaram, em rendimento de plantas comerciáveis, com uma produção de $33,86 \mathrm{t} / \mathrm{ha}$. Porto (1999) avaliou cinco cultivares de alface em sistemas solteiro e consorciado com cenoura nas condições de Mossoró$\mathrm{RN}$, e observou que a cultivar Babá de Verão sobressaiu-se das demais em termos de produtividade, independentemente do sistema de cultivo utilizado. 
A produção de uma espécie é função da interação entre o genótipo das plantas e as condições ambientais. Entre os fatores que afetam a condição do meio está o número de plantas por unidade de área (Mondim, 1988). A alface, como os demais cultivos, também responde aos efeitos provocados pelos espaçamentos utilizados, os quais exercem grande influência no comportamento das plantas, afetando-lhes a arquitetura, o desenvolvimento, o peso, a qualidade e, consequentemente, a produção. Esta tende a aumentar com o aumento da população de plantas por unidade de área, embora nem sempre se obtenha produtos de alto valor comercial (Janick, 1986). Ramos (1995) trabalhando nas condições de Mossoró-RN tem sugerido espaçamentos maiores do que $25 \mathrm{x}$ $25 \mathrm{~cm}$ para a alface.

Objetivando fornecer maiores subsídios para o desenvolvimento de tecnologias para produção da alface, o presente trabalho teve como objetivo avaliar três cultivares de alface em seis espaçamentos de plantio sob condição de temperatura e luminosidade elevadas no município de Mossoró-RN.

\section{MATERIAL E MÉTODOS}

O experimento foi conduzido na Horta do Departamento de Fitotecnia da ESAM, no período de junho a julho de 1998, em solo classificado como Podzólico Vermelho-Amarelo Equivalente Eutrófico (Brasil, 1971), Grande Grupo Eutrustalfs do 'Soil Taxonomy'. Da área experimental, foram retiradas amostras, cuja análise, processada no Laboratório de Química e Fertilidade de Solos da referida Escola, revelou os seguintes resultados: $\mathrm{pH}$ (água 1:2,5) $=7,9 ; \mathrm{Ca}=$ $6,8 \mathrm{cmolc} \mathrm{dm}^{-3} ; \mathrm{Mg}=3,2 \mathrm{cmolc} \mathrm{dm}^{-3} ; \mathrm{K}$ $=0,64 \mathrm{cmolc} \mathrm{dm}^{-3} ; \mathrm{Na}=0,84 \mathrm{cmolc} \mathrm{dm}^{-3}$. $\mathrm{Al}=0,00 \mathrm{cmolc} \mathrm{dm}^{-3}$ e $\mathrm{P}=388 \mathrm{mg} \mathrm{dm}^{-3}$.

O município de Mossoró está situado a $5^{0} 11^{\prime}$ de latitude sul e $37^{\circ} 20^{\prime}$ de longitude oeste e altitude de $18 \mathrm{~m}$. O clima da região, segundo a classificação de Thornthwaite, é semi-árido e, de acordo com Köeppen é BSwh', seco e muito quente, com duas estações climáticas: uma seca, que vai geralmente de junho a janeiro, e uma chuvosa, de fevereiro a maio (Carmo Filho \& Oliveira, 1989).

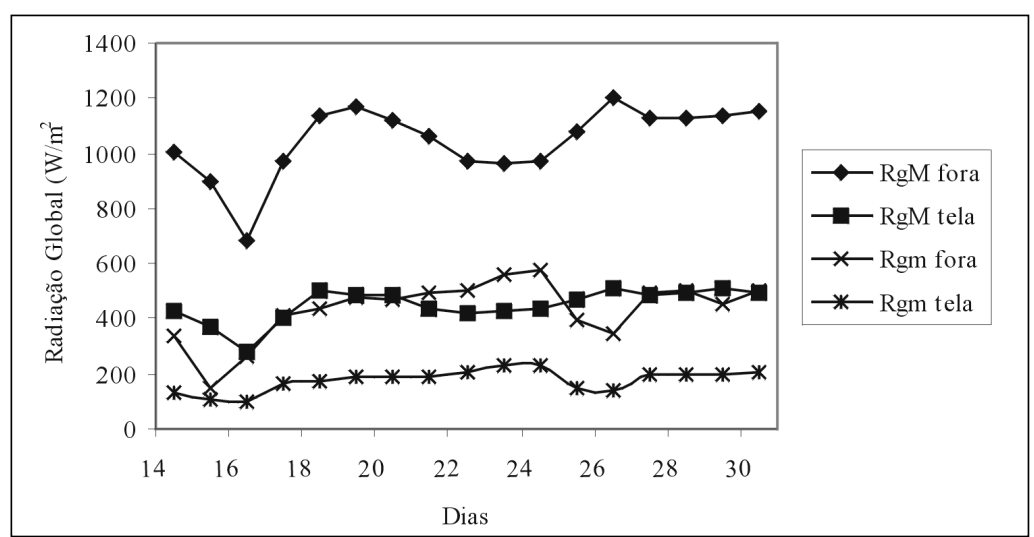

Figura 1. Valores máximos (RgM) e médios (Rgm) da radiação global, fora e sob a tela no período de 14 à 30 de junho de 1998. Mossoró, ESAM, 1998.

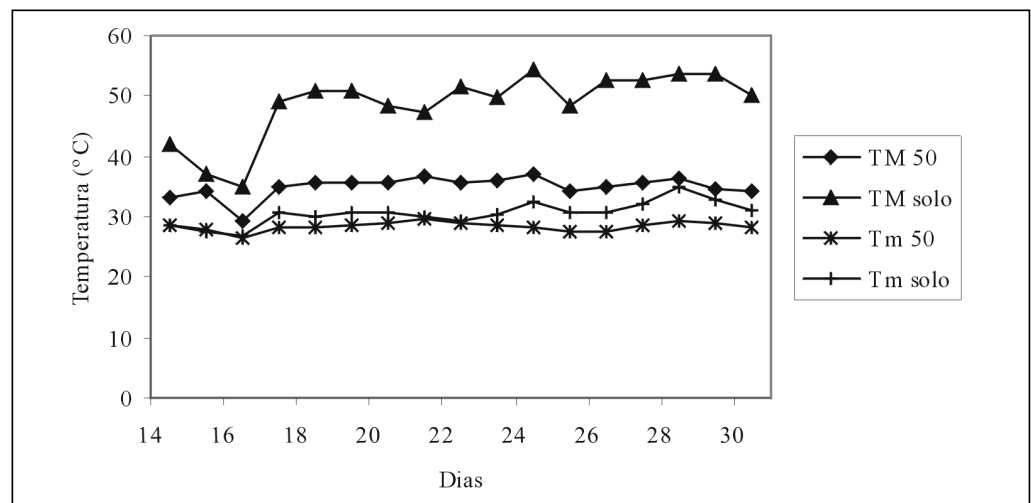

Figura 2. Valores máximos (TM) e médios (Tm) da temperatura do solo e do ar a $50 \mathrm{~cm}$ do leito da sementeira no período de 14 a 30 de junho de 1998. Mossoró, ESAM, 1998.

O delineamento experimental utilizado foi blocos casualizados completos, em esquema fatorial $3 \times 6+1$ (tratamento adicional), com quatro repetições. O primeiro fator foi constituído pelas cultivares Great Lakes (grupo crespa repolhuda), Elisa (grupo lisa) e Babá de Verão (grupo lisa repolhuda), selecionadas entre as melhores de cada grupo, em ensaios de outras regiões do nordeste brasileiro, e o segundo fator pelos espaçamentos $20 \times 20 \mathrm{~cm}, 20 \mathrm{x}$ $25 \mathrm{~cm}, 20 \times 30 \mathrm{~cm}, 25 \times 25 \mathrm{~cm}, 25 \times 30$ $\mathrm{cm}$ e $30 \times 30 \mathrm{~cm}$. O tratamento adicional (tratamento onde as plantas de alface foram sombreadas com tela de nylon na sementeira e no campo, como uma tentativa para amenizar os efeitos da temperatura e luminosidade elevadas) constou da cultivar Great Lakes plantada no espaçamento $20 \times 20 \mathrm{~cm}$ e sombreada durante todo o ciclo cultural. Este tratamento foi usado para se comparar com o 'tratamento especial' (testemu- nha), proveniente da combinação da Great Lakes com o espaçamento de 20 x $20 \mathrm{~cm}$, sombreada apenas na sementeira, com o intuito de se verificar a viabilidade do sombreamento durante todo o ciclo da alface. O tratamento testemunha tem sido usado pelos produtores da região Oeste do Rio Grande do Norte. As parcelas experimentais apresentaram uma área total de $1,80 \mathrm{~m}^{2}$.

Durante a fase de produção de mudas, foram determinadas com o auxílio de uma Estação Meteorológica portátil, a radiação solar global em condições normais e de sombreamento, a temperatura do ar a $50 \mathrm{~cm}$ da sementeira e a temperatura do solo (Figuras 1 e 2). Para a produção das mudas foram utilizados copos descartáveis de plástico com o formato de cone, de $8 \mathrm{~cm}$ de diâmetro superior, $5,5 \mathrm{~cm}$ de diâmetro inferior e $13 \mathrm{~cm}$ de altura, conforme recomendações feitas por Ramos (1995). Para o enchimento dos recipientes utilizou-se o 
Tabela 1. Altura e diâmetro de plantas $(\mathrm{cm})$, número de folhas por planta e massa seca da parte aérea (t/ha) de alface em função de cultivares e espaçamentos. Mossoró, ESAM, 1998.

\begin{tabular}{|c|c|c|c|c|}
\hline \multirow[b]{2}{*}{ Cultivares } & \multicolumn{4}{|c|}{ Características } \\
\hline & \multirow{2}{*}{$\begin{array}{c}\begin{array}{c}\text { Altura de } \\
\text { plantas }\end{array} \\
20,10 a^{=}\end{array}$} & \multirow{2}{*}{$\begin{array}{c}\begin{array}{c}\text { Diâmetro de } \\
\text { plantas }\end{array} \\
31,00 a\end{array}$} & $\begin{array}{c}\text { No de } \\
\text { folhas/planta }\end{array}$ & $\begin{array}{c}\text { Massa seca da } \\
\text { parte aérea }\end{array}$ \\
\hline Great Lakes & & & $15,08 \quad c$ & $5,99 a$ \\
\hline Elisa & $18,22 b$ & $29,94 a$ & $30,29 a$ & $5,47 a$ \\
\hline Babá de Verão & $17,25 \mathrm{~b}$ & $27,16 \mathrm{~b}$ & $27,96 \mathrm{~b}$ & $6,00 a$ \\
\hline Great Lakes sombreada na sementeira & $21,83 \mathrm{~A}$ & $30,50 \mathrm{~A}$ & $13,25 \mathrm{~A}$ & $8,19 A$ \\
\hline Great Lakes sombreada em todo ciclo & $22,59 \mathrm{~A}$ & $30,59 \mathrm{~A}$ & $12,75 \mathrm{~A}$ & $6,68 \mathrm{~B}$ \\
\hline \multicolumn{5}{|l|}{ Espaçamento (cm) } \\
\hline $20 \times 20$ & $19,94 a$ & $27,31 b$ & $23,67 a$ & $8,55 a$ \\
\hline $20 \times 25$ & $18,95 a b$ & $28,58 a b$ & $24,25 a$ & $6,79 \mathrm{~b}$ \\
\hline $20 \times 30$ & $18,46 a b$ & $30,17 a$ & $24,58 a$ & $5,98 \mathrm{bc}$ \\
\hline $25 \times 25$ & $18,03 a b$ & $28,95 a b$ & $24,83 a$ & $5,15 \mathrm{~cd}$ \\
\hline $25 \times 30$ & $17,87 \mathrm{~b}$ & $30,32 a$ & $25,17 a$ & 4,49 \\
\hline $30 \times 30$ & $17,89 b$ & $30,88 a$ & $24,17 a$ & 3,97 \\
\hline C.V. (\%) & 9,10 & 7,73 & 11,82 & 19,05 \\
\hline
\end{tabular}

${ }^{+}$Nas colunas, as médias seguidas pela mesma letra minúscula ou maiúscula não diferem significativamente entre si pelo teste de Tukey, e pela mesma letra maiúscula não diferem entre si pelo teste "t" no nível de $5 \%$ de probabilidade.

substrato comercial Nutriplant, constituído de vermiculita expandida e composto vegetal, isento de pragas e doenças.

A semeadura foi efetuada em 8 de junho de 1998. A partir da emergência até o dia do transplante, todas mudas, com exceção daquelas do tratamento adicional (sombreadas durante todo o ciclo da cultura) foram sombreadas com uma tela de 'nylon', de cor preta com malha de 2 × $2 \mathrm{~mm}$, colocada a $25 \mathrm{~cm}$ de altura do leito da sementeira. Aos oito dias após a emergência foi efetuado o desbaste, deixando-se uma muda por recipiente, e aos 15 dias foi realizada uma adubação foliar com a formulação $14 \% \mathrm{~N} ; 4 \%$ $\mathrm{P}_{2} \mathrm{O}_{5} ; 6 \% \mathrm{~K} \mathrm{O} ; 0,8 \% \mathrm{~S} ; 1,5 \% \mathrm{Mg} ; 2 \%$ $\mathrm{Zn} ; 1,5 \% \mathrm{Mn} ; 0,1 \% \mathrm{~B}$ e $0,05 \% \mathrm{Mo}$, à base de $30 \mathrm{~g} / 20$ litros de água.

A cultura foi estabelecida por transplante direto em canteiros de 1,20 m de largura e $0,20 \mathrm{~m}$ de altura. O transplante foi realizado em 30 de junho de 1998, quando as mudas apresentavam de quatro a seis folhas definitivas.

Diariamente, foram efetuadas irrigações por micro-aspersão, uma pela manhã e duas à tarde, de forma a manter o teor de água no solo próximo à capacidade de campo. Foram realizadas duas capinas manuais visando à manutenção da cultura sempre no limpo. Efetuaram- se duas adubações nitrogenadas, sendo a primeira uma semana após o transplante, utilizando-se $20 \mathrm{~g} / \mathrm{m}^{2}$ de sulfato de amônio e a segunda, via foliar, uma semana após a primeira, na dosagem de $10 \mathrm{~g}$ de uréia para 10 litros de água. Em seguida, efetuou-se uma irrigação visando à retirada de partículas de adubo das folhas.

A colheita foi efetuada em 24 de julho de 1998, aos 47 dias da semeadura, quando as plantas atingiram o máximo desenvolvimento vegetativo. Foram avaliadas a altura e diâmetro de plantas; número de folhas por planta; massa seca da parte aérea; produtividade; renda bruta; renda líquida e taxa de retorno. A renda bruta foi obtida multiplicando-se a produtividade de cada tratamento pelo valor do produto obtido, que foi de R\$ 0,50 por quilo, pago ao produtor no quadrimestre abril-julho de 1998, independentemente do tamanho e do tipo da alface. A renda líquida foi calculada subtraindo-se da renda bruta, os custos de produção, provenientes de insumos mais serviços. Estes custos foram calculados para cada tratamento, já que o número de plantas variou de acordo com o tratamento e também baseado nos coeficientes de custo de insumos e serviços utilizados em um hectare de alface em nível experimental. Foram considerados os preços de insumos e serviços vigentes no quadrimestre abriljulho de 1998, na cidade de MossoróRN. A taxa de retorno por real investido em cada tratamento foi obtida por meio da relação entre a renda bruta e o custo de produção de cada tratamento.

As análises estatísticas para as características avaliadas foram efetuadas em 'software' SPSS/PC. Para a comparação das médias provenientes dos fatores tratamentos cultivares $\mathrm{e}$ espaçamentos, usou-se o teste Tukey no nível de $5 \%$ de probabilidade enquanto para a comparação das médias do tratamento adicional e do tratamento especial, usou-se o teste ' $t$ ' de Student, no nível de $5 \%$ de probabilidade.

\section{RESULTADOS E DISCUSSÃO}

Houve efeito significativo dos fatores cultivar e espaçamento na altura e diâmetro de plantas de alface (Tabela 1). A cultivar Great Lakes foi a que apresentou maior altura e diâmetro de plantas, embora não tenha diferido significativamente da cultivar Elisa com relação a esta última característica. Estes resultados concordam com os de Ramos (1995), onde a Great Lakes se destacou em termos de altura e diâmetro de plan- 
Tabela 2. Produtividade de alface (t/ha) em função de cultivares e espaçamentos. Mossoró, ESAM,1998.

\begin{tabular}{|c|c|c|c|c|c|c|}
\hline \multirow{2}{*}{ Cultivares } & \multicolumn{6}{|c|}{ Espaçamentos (cm) } \\
\hline & $20 \times 20$ & $20 \times 25$ & $20 \times 30$ & $25 \times 25$ & $25 \times 30$ & $30 \times 30$ \\
\hline Great Lakes & $31,25 \mathrm{Aa}$ & $23,53 \mathrm{Abc}$ & $27,67 \mathrm{Aab}$ & $21,60 \mathrm{Abc}$ & $19,92 A \quad C$ & $21,72 A \quad c++$ \\
\hline Elisa & $27,44 \mathrm{Aa}$ & $20,08 \mathrm{Abc}$ & 22,04Aab & $17,57 \mathrm{Abc}$ & $19,78 \mathrm{Abc}$ & $13,98 \mathrm{Bc}$ \\
\hline Babá de Verão & $29,71 \mathrm{Aa}$ & $27,81 \mathrm{Aa}$ & $20,10 \mathrm{Ab}$ & $20,73 A b$ & $19,39 \mathrm{Ab}$ & $14,81 \mathrm{Bb}$ \\
\hline $\begin{array}{l}\text { Great Lakes sombr. em } \\
\text { todo ciclo }\end{array}$ & 18,05 & & & $\%)=1$ & & \\
\hline
\end{tabular}

+ A Great Lakes sombreada apenas na sementeira diferiu significativamente da sombreada durante todo o ciclo no nível de 5\% de probabilidade pelo teste " $\mathrm{t}$ ".

++ Médias seguidas pelas mesmas letras minúsculas nas linhas e maiúsculas nas colunas não diferem significativamente entre si pelo teste de Tukey no nível de $5 \%$ de probabilidade..

tas. Quando se comparou os valores médios destas características da cultivar Great Lakes, que recebeu sombreamento apenas na fase de sementeira, com os valores médios desta cultivar que recebeu sombreamento durante todo o ciclo, ambas no espaçamento de $20 \times 20 \mathrm{~cm}$, verificou-se que eles não diferiram estatisticamente entre si (Tabela 1 ).

O espaçamento de $20 \times 20 \mathrm{~cm}$ foi o que proporcionou maior altura de plantas, embora não tenha diferido dos espaçamentos $20 \times 25 \mathrm{~cm}, 20 \times 30 \mathrm{~cm}$ e $25 \times 25 \mathrm{~cm}$. Acredita-se que a maior competição por luz nos espaçamentos mais adensados contribuiu para que as plantas atingissem alturas mais elevadas. Este resultado vem corroborar a afirmação de Gangnebin \& Bonnet (1978), que espaçamentos maiores contribuem para retardar o crescimento do caule principal. Por outro lado, os espaçamentos de $25 \times 30 \mathrm{~cm}$ e $30 \times 30$ $\mathrm{cm}$ foram os que apresentaram maiores diâmetros de plantas de alface, não diferindo estatisticamente de $25 \times 25 \mathrm{~cm}$, $20 \times 30 \mathrm{~cm}$ e $20 \times 25 \mathrm{~cm}$ (Tabela 1). Sabe-se que espaçamentos maiores proporcionam menor competição entre plantas, com consequente maior diâmetro de plantas.

Para o número de folhas por planta, observou-se efeito significativo apenas do fator cultivar (Tabela 1). A cultivar Elisa foi a que apresentou o maior número de folhas por planta, com o dobro da cultivar Great Lakes (Tabela 1). Este resultado concorda em parte com os encontrados por Ramos (1995), que mostra um menor número de folhas por planta na cultivar Great Lakes, na ocasião da colheita, quando comparada com as cultivares Verdinha e Babá de Verão. Estas diferenças nesta variável são devidas às características de cada cultivar.

Não se constatou diferença significativa para o número de folhas por planta entre a cultivar Great Lakes sombreada na sementeira e a sombreada durante todo o ciclo.

Para massa seca da parte aérea foi observado efeito significativo apenas do fator espaçamento, com o espaçamento de $20 \times 20 \mathrm{~cm}$ registrando o maior valor (Tabela 1). À medida que se aumentou o espaçamento entre plantas de alface houve um decréscimo significativo na produção de massa seca da parte aérea.

Maior produção de massa seca da parte aérea (da ordem de 23\%) foi obtida quando a cultivar Great Lakes foi sombreada somente na sementeira quando comparada com a sombreada durante todo o ciclo cultural (Tabela 1). Provavelmente o sombreamento durante todo o ciclo inibiu a expressão de todo o seu potencial. Isto está de acordo com o reportado por Edmond et al. (1967).

Houve efeito significativo da interação cultivar e espaçamento na produtividade de alface. $\mathrm{O}$ desdobramento desta interação registrou rendimentos diferentemente significativos nos espaçamentos dentro de cada cultivar estudada (Tabela 2). As maiores produtividades foram registradas no espaçamento $20 \times 20 \mathrm{~cm}$ nas cultivares de alface Great Lakes e Elisa e nos espaçamentos de 20 x $20 \mathrm{~cm}$ e de 20 x $25 \mathrm{~cm}$ na cultivar Babá de Verão (Tabela 2). Estes resultados discordam da afirmação de Ramos (1995), que recomenda espaçamentos maiores de $25 \times 25 \mathrm{~cm}$ para a Região Nordeste. Por outro lado, quando se desdobrou a interação cultivar dentro de cada espaçamento, verificou-se que as cultivares diferiram de maneira significativa, apenas dentro do espaçamento de $30 \times 30 \mathrm{~cm}$, com a cultivar Great Lakes se destacando da Elisa e da Babá de Verão (Tabela 2).

Houve diferença significativa entre a produtividade da cultivar Great Lakes que recebeu sombreamento na sementeira e a que recebeu sombreamento durante todo o ciclo (Tabela 2). Esta diferença foi de $73 \%$ a mais na produtividade da Great Lakes sombreada apenas na sementeira. Isto se deve, provavelmente, à inibição no desenvolvimento das plantas de alface causada pelo sombreamento durante todo o ciclo cultural, impedindo-as de alcançar todo o seu potencial morfo-fisiológico. Baseado nisto, faz-se necessário alertar para a necessidade de sombreamento apenas na fase de formação de mudas, quando as plantas estão mais suscetíveis aos efeitos da luminosidade e da temperatura.

De modo geral, as maiores rendas bruta e líquida e taxa de retorno foram registradas no espaçamento de $20 \times 20$ $\mathrm{cm}$, com a cultivar Great Lakes, destacando-se das demais, com valores de R\$ $15.625,00$ para a renda bruta, de $\mathrm{R} \$$ 9.198,00 para a renda líquida e 2,43 para a taxa de retorno (Tabela 3). Estes valores superaram os normalmente obtidos por produtores da região, que são de: $\mathrm{R} \$$ 4.800.00 para renda bruta, $\mathrm{R} \$ 2.155,00$ para a renda líquida e 1,81 para a taxa de retorno. Esses resultados demonstram a viabilidade da adoção destas tecnologias, pois elas contribuem para a produção de alface de boa qualidade, sob temperatura e luminosidade elevadas. 
Comportamento de cultivares de alface em diferentes espaçamentos sob temperatura e luminosidade elevadas.

Tabela 3. Indicadores econômicos de rendas bruta e líquida e taxa de retorno em reais (1,00) para a cultura de alface. Mossoró, ESAM, 1998.

\begin{tabular}{lcccc}
\hline Cultivares & Espaçamentos & Renda bruta & Renda líquida & Taxa de retorno \\
\hline Great Lakes & $20 \times 20$ & 15325 & 9198 & 2,43 \\
& $20 \times 25$ & 11765 & 5338 & 1,83 \\
& $20 \times 30$ & 13835 & 7408 & 2,15 \\
& $25 \times 25$ & 10800 & 4373 & 1,68 \\
& $25 \times 30$ & 9600 & 3533 & 1,55 \\
\hline Elisa & $30 \times 30$ & 10860 & 4433 & 1,69 \\
\hline $20 \times 20$ & 13720 & 7293 & 1,56 \\
& $20 \times 25$ & 10040 & 3613 & 1,75 \\
& $20 \times 30$ & 11020 & 4593 & 1,37 \\
\hline Babá de Verão & $25 \times 25$ & 8785 & 3463 & 1,54 \\
& $25 \times 30$ & 9890 & 563 & 1,09 \\
\hline $30 \times 30$ & 6990 & 8428 & 2,31 \\
& $20 \times 20$ & 14855 & 7473 & 2,16 \\
& $20 \times 25$ & 13900 & 3623 & 1,56 \\
& $20 \times 30$ & 10050 & 3938 & 1,61 \\
& $25 \times 25$ & 10365 & 3268 & 1,51 \\
& $30 \times 30$ & 9695 & 970 & 1,15 \\
\hline
\end{tabular}

\section{LITERATURA CITADA}

BRASIL, Ministério da Agricultura. Levantamento exploratório - reconhecimento de solos do Estado do Rio Grande do Norte. Recife: DNPEA/SUDENE/USAID, 1971. (DPP. Boletim 21, PE 13).

CARMO FILHO, F.; OLIVEIRA, 0. F. Mossoró: um município semi-árido nordestino - características e aspectos florísticos. Mossoró: ESAM, 1989. 62 p. (Coleção Mossoroense B, 672).

EDMOND, J.B.; SENN, T.L.; ANDREWS, F.S. La luz como factor limitante. In: EDMOND, J.B.; SENN, T.L.; ANDREWS, F.S. Princípios de horticultura. Mexico: Continental, 1967. p. 119-134.

GANGNEBIN, F.; BONNET, J.C. Some effects of spacing on the growth and development of lettuce. Revue Horticole Suisse, v. 51, n. 12, p. $345-348,1978$.
JANICK, J.V. A Ciência da horticultura. São Paulo: Freitas Bastos S. A., 1986. 486p.

LEAL, F.R.; SOUZA, A.M.M. Comportamento de sete cultivares de alface pelo sistema tradicional de plantio. Horticultura Brasileira, Brasília, v. 9, n. 1, p. 42, 1991.

LYRA FILHO, H.P.; MARANHÃO, E.H.A.; WANDERLEY, L.J.G. Comportamento de cultivares de alface (Lactuca sativa L.), tipo folha lisa em Vitória de Santo Antão-PE, Horticultura Brasileira, Brasília, v. 12, n. 1, p. 87, 1994.

MAKISHIMA, N. Cultivo de hortaliças. Brasília: CNPH, 1992. 26 p.

MONDIM, M. Influencia de espaçamentos, métodos de plantio e de sementes nuas e peletizadas na produção de duas cultivares de alface. Lavras: UFLA, 1988. 59 p. (Dissertação mestrado).
PORTO, V.C.N. Cultivares de alface em sistema solteiro e consorciado com cenoura sob temperatura e luminosidade elevadas. Mossoró: ESAM, 1999. (Dissertação mestrado).

RAMOS. J.E.L. Sombreamento e tipos de recipientes na formação de mudas e produção de alface. Mossoró: ESAM, 1995. 53 p. (Dissertação mestrado)

SETUBAL, W.J.; SILVA, A.R. Avaliação do comportamento de alface de verão em condições de calor no município de Teresina-PI. Teresina: UFPI, 1992. 17 p. (Mimeografado). 